\title{
MIMO Antenna H-Plane Isolation Enhancement using UC-EBG Structure and Metal Line Strip for WLAN Applications
}

\author{
Niraj KUMAR, Usha Kiran KOMMURI \\ School of Electronics Engineering, Vellore Institute of Technology Chennai Campus, Chennai, India, 600127 \\ nirajkumar@vit.ac.in, usha.kiran@vit.ac.in \\ Submitted October 4, 2018 / Accepted March 11, 2019
}

\begin{abstract}
This paper presents design of novel uniplanar compact Electromagnetic Band Gap (EBG) structure and its application in enhancement of isolation in H-Plane of MIMO antenna system for WLAN $(5.8 \mathrm{GHz})$. Isolation enhancement or coupling reduction of $5.6 \mathrm{~dB}$ is achieved by etching out the proposed EBG structure from the ground plane of microstrip patch MIMO antenna. Center to center distance is reduced to $0.45 \lambda_{0}$ due to compactness of EBG. A metal line strip between radiating patches is used for further reduction in mutual coupling at $5.8 \mathrm{GHz}$. There is significant enhancement of $16.2 \mathrm{~dB}$ in isolation due to the introduction of metal line strip. Hence the total $21.8 \mathrm{~dB}$ reduction in mutual coupling is achieved and this coupling reduction is also verified by surface current plots and measured result. The envelope correlation coefficient (ECC) is less than 0.01 and channel capacity loss (CCL) is less than $0.1 \mathrm{bps} / \mathrm{Hz}$ at operating frequency.
\end{abstract}

\section{Keywords}

Electromagnetic Band Gap (EBG), MIMO antenna, mutual coupling

\section{Introduction}

With increased demand of MIMO antennas in wireless communication systems, the mutual coupling between the antenna elements has become one of the concerned problems. More and more researches are focused on compactness of multi-antenna systems due to increasing miniaturization of RF systems. This compactness leads to high mutual coupling between the antenna elements and causes distortion of the radiation characteristics. Many effective methods and techniques have been investigated to reduce the mutual coupling as well as increase the compactness between antenna elements of MIMO antenna system. Defective ground structure [1], metamaterial [2], [3], different shapes of resonators [4], [5], uniplanar electromagnetic band gap structures [6-13] are mostly used methods. Double layer electromagnetic band gap structures [14], [15],
1-D EBG combined with split ring resonator (SRR) [16], high impedance surfaces (HIS) [17] have also been used. Inexpensive manufacturing and reduced complexity of uniplanar compact EBG makes it best choice for MIMO antenna coupling reduction. Most of the researches concentrate on mutual coupling reduction in E-plane. Very few works are available for mutual coupling reduction in H-plane [2, 3, 5, 7, 9].

In this paper, a new uniplanar compact electromagnetic bandgap structure with metal strip line is proposed. This structure reduces mutual coupling in H-plane for closely spaced co-planar radiating microstrip patch antennas with center to center spacing of $0.45 \lambda_{0}$. Design methodology and band-gap analysis of the proposed UC-EBG unit cell is described in Sec. 2. In Sec. 3 simulated design of MIMO antenna and application of proposed EBG to reduce the mutual coupling of MIMO antenna are presented. Further isolation enhancement by integrating one metal line strip between antennas is described in Sec. 4. Fabrication and result analysis of proposed MIMO antenna systems is presented in Sec. 5. Section 6 contains the conclusion of research.

\section{Design Methodology of Comb Shape Electromagnetic Bandgap Structure for WLAN}

Unit cell of proposed electromagnetic band gap structure is designed by combination of swastika with four square comb shape structures rotated at $90^{\circ}$ with each other. Low cost substrate FR4 with dielectric constant 4.4 and height $1.6 \mathrm{~mm}$ is used for EBG structure design as shown in Fig. 1. Area of $6.8 \times 6.8 \mathrm{~mm}^{2}$ is utilized for the proposed EBG that results in compactness of MIMO antenna system. Optimized values of design parameters of the unit cell of EBG for resonance at $5.8 \mathrm{GHz}$ (WLAN) are given in Fig. 1. The equivalent circuit of the proposed EBG is shown in Fig. 2. All the design simulations and analysis has been done using ANSYS High Frequency Structural Simulator (HFSS). 


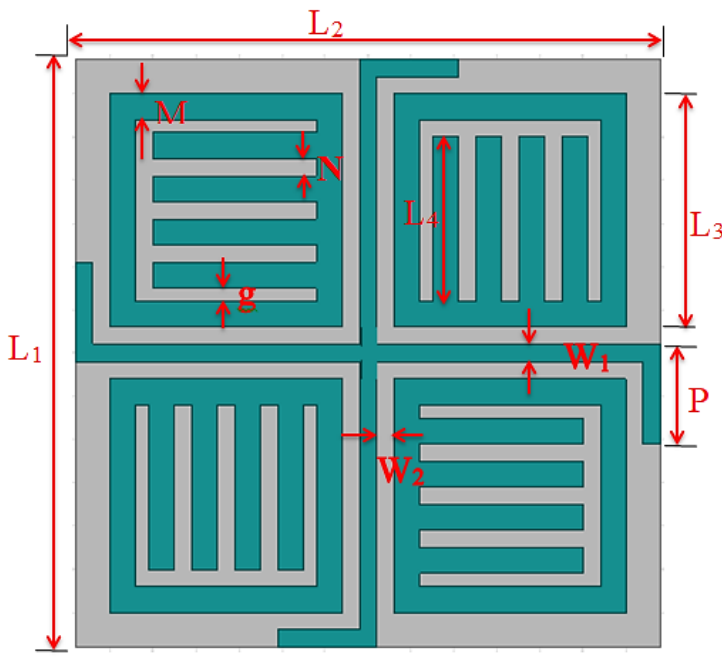

Fig. 1. Unit structure of the proposed EBG. (L1 $=6.8 \mathrm{~mm}$, $\mathrm{L} 2=6.8 \mathrm{~mm}, \mathrm{~L} 3=2.7 \mathrm{~mm}, \mathrm{~L} 4=1.9 \mathrm{~mm}, \mathrm{M}=0.3 \mathrm{~mm}$, $\mathrm{N}=0.25 \mathrm{~mm}, \mathrm{P}=1.15 \mathrm{~mm}, \mathrm{~W} 1=0.2 \mathrm{~mm}, \mathrm{~W} 2=0.2 \mathrm{~mm}$, $\mathrm{g}=0.15 \mathrm{~mm})$.



Fig. 2. Equivalent circuit of the proposed EBG.

\begin{tabular}{|c|c|c|c|c|c|}
\hline Parameters & $\mathbf{C 1}(\mathbf{p F})$ & $\mathbf{C 2}(\mathbf{p F})$ & $\mathbf{C 3}(\mathbf{p F})$ & $\mathbf{L 1}(\mathbf{n H})$ & $\mathbf{L 2}(\mathbf{n H})$ \\
\hline Values & 0.28 & 0.16 & 1.07 & 13.8 & 3.8 \\
\hline
\end{tabular}

Tab. 1. Optimized values of parameters of equivalent circuit of the unit cell of the proposed EBG.

In Fig. $2 \mathrm{~L}_{1}$ is inductance due to each square comb shape structure and $\mathrm{L}_{2}$ is inductance due to swastika sign structure at the center. $\mathrm{C}_{1}$ is induced capacitance between ground and each square comb shape structure. $\mathrm{C}_{2}$ is capacitance between each square comb shape structure and swastika structure. $\mathrm{C}_{3}$ is induced capacitance between ground and swastika structure. Optimized values of $\mathrm{L}_{1}, \mathrm{~L}_{2}$, $\mathrm{C}_{1}, \mathrm{C}_{2}$ and $\mathrm{C}_{3}$ for resonance at $5.8 \mathrm{GHz}$ are given in Tab. 1 .

Resonance and working frequency of unit cell of proposed EBG is also analyzed by transmission line analysis. Setup for the analysis in HFSS is shown in Fig. 3. $50 \Omega$ transmission line of width $3 \mathrm{~mm}$ has been created on FR4 substrate and the proposed EBG has been etched out of the ground plane. Two lumped ports are created at each side of the transmission line and simulated with radiation box covering the whole system. Changes in length of lines or copper strip on grounded substrate contribute to the changes

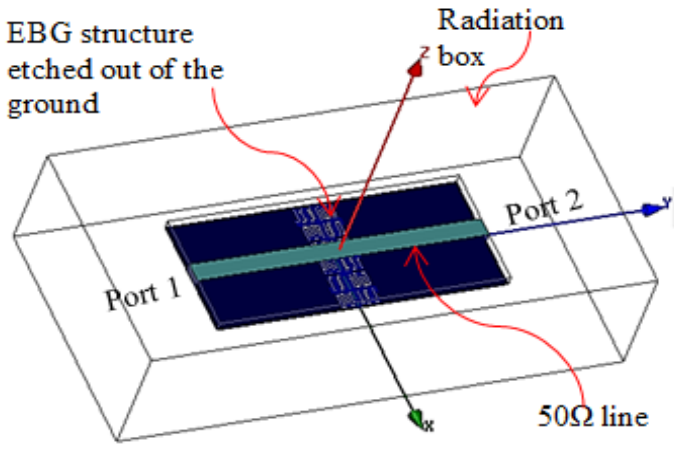

Fig. 3. Simulation setup for transmission line analysis.

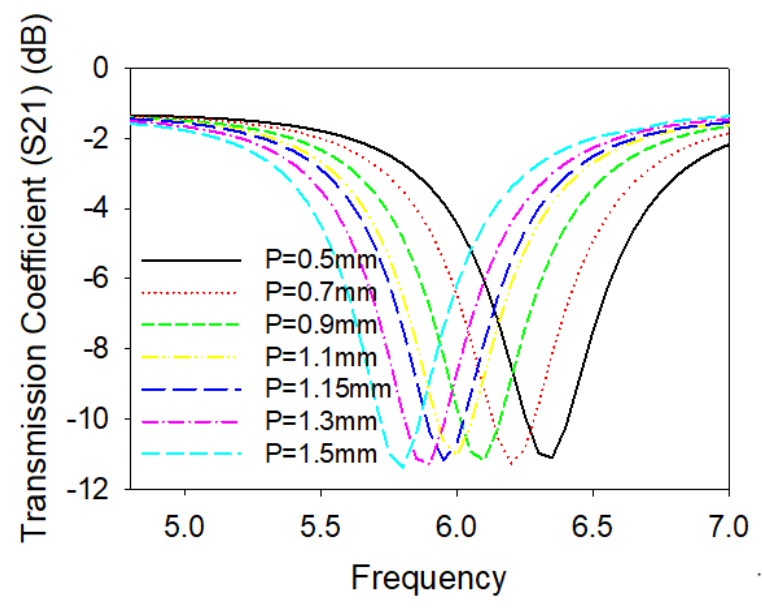

Fig. 4. Effect of changes $\mathrm{P}=0.5$ to $1.5 \mathrm{~mm}$ of the proposed EBG unit cell on transmission coefficient.

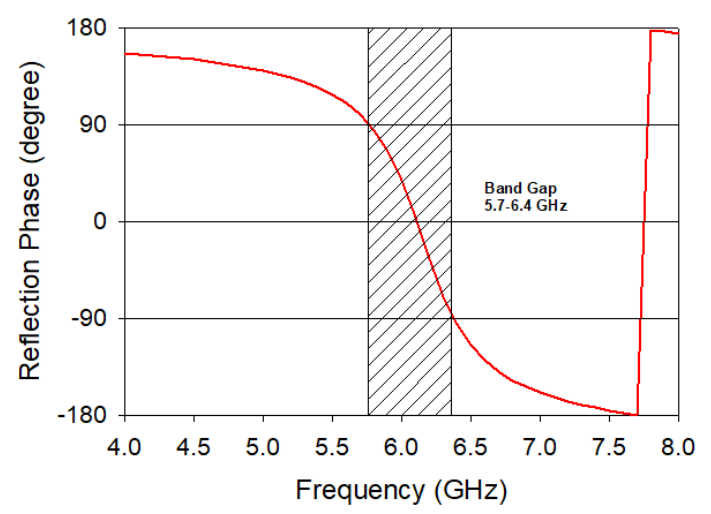

Fig. 5. Reflection phase diagram of the proposed EBG unit cell.

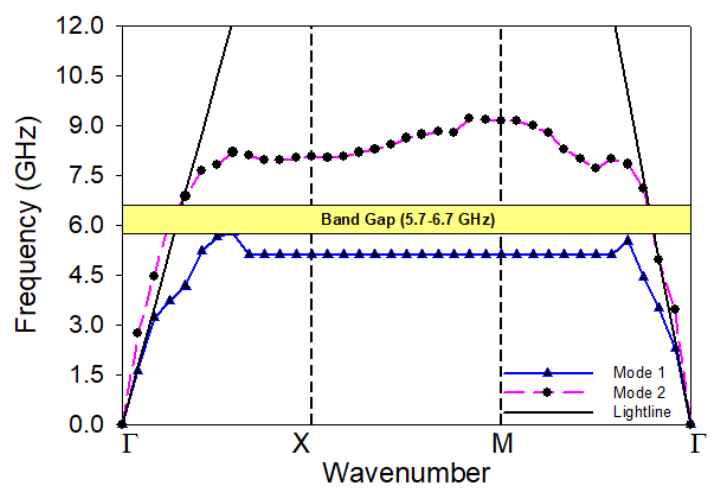

Fig. 6. Dispersion diagram of the proposed EBG unit cell using Eigen mode analysis. 
in inductance and capacitance values that result in changed resonance frequency. Variation of resonance frequency due to change in length $P$ of swastika shape arm is shown in Fig. 4. If $P$ is changed from $0.5 \mathrm{~mm}$ to $1.5 \mathrm{~mm}$ resonance frequency changes from $6.3 \mathrm{GHz}$ to $5.7 \mathrm{GHz}$. For resonant frequency of $5.8 \mathrm{GHz}$, the optimized value of $P$ is considered as $1.15 \mathrm{~mm}$ from the graph of Fig. 4 .

The proposed structure is further analyzed for band gap properties using reflection phase diagram and dispersion diagram methods [18], [19]. Reflection phase diagram is plotted in Fig. 5. To plot the reflection phase diagram, periodic boundary conditions (PBC) have been used. Reflection phase of $+90^{\circ}$ to $-90^{\circ}$ gives frequency band gap of 5.7-6.4 GHz. Dispersion diagram of the proposed EBG unit cell is plotted in Fig. 6 using Eigen mode analysis, and frequency band gap of $5.7-6.7 \mathrm{GHz}$ is achieved. The design frequency $(5.8 \mathrm{GHz})$ of MIMO antenna is well within the frequency band gap achieved by all above presented methods.

\section{Implementation of Comb-shaped EBG in Mutual Coupling Reduction of H-coupled MIMO Antenna for WLAN}

Basic inset feed microstrip patch antenna for WLAN is considered with dimensions as depicted in Fig. 7 and MIMO antenna of size $46 \mathrm{~mm} \times 20 \mathrm{~mm}$ is designed with placing two antennas with edge to edge gap of $7.86 \mathrm{~mm}$ i.e. $0.15 \lambda_{0}$ and center to center gap of $0.45 \lambda_{0}$ with two ports as shown in Fig. 8.

Magnetic field in MIMO antenna gets coupled through the non-radiating edges. $3 \times 1$ unit cells placed adjacent to each other has been etched out from the ground surface between non-radiating edges (H-plane) as shown in Fig. 8. From Fig. 9(a) it is clear that frequency of resonance is not affected by the integration of EBG into the MIMO system. The transmission coefficient (coupling in $\mathrm{H}$-plane) between antennas got reduced to $22.1 \mathrm{~dB}$ from $16.5 \mathrm{~dB}$ (5.6 dB reduction) as shown in Fig. 9(b).

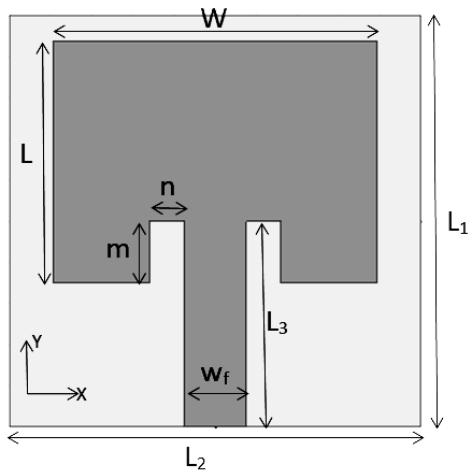

Fig. 7. Microstrip patch antenna for WLAN $(\mathrm{L}=11.75 \mathrm{~mm}$, $\mathrm{L} 1=15.74 \mathrm{~mm}, \mathrm{~L} 2=20 \mathrm{~mm}, \mathrm{~L} 3=18 \mathrm{~mm}, \mathrm{~W}=10 \mathrm{~mm}$, $\mathrm{Wf}=3 \mathrm{~mm}, \mathrm{~m}=3 \mathrm{~mm}, \mathrm{n}=1.7 \mathrm{~mm}$ )


Fig. 8. Microstrip patch MIMO antenna for WLAN: (a) front view, (b) ground with EBG.

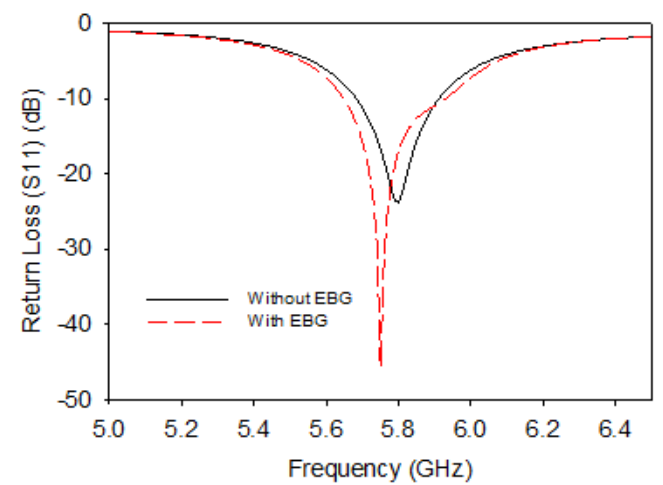

(a)

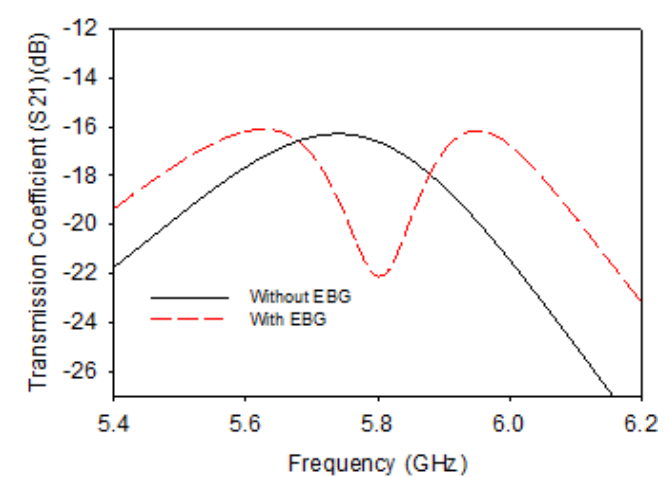

(b)

Fig. 9. Simulated (a) return loss (S11) and (b) transmission coefficient (S21) of MIMO antenna with and without the proposed EBG.

\section{Further Enhancement in Isolation of WLAN MIMO Antenna}

As observed in most of the work, mutual coupling reduction in H-plane is very low by using EBG alone in the same plane as antennas. Hence we have used the EBG in ground plane and kept the top plane for further possibilities of combination with different structures. Few works used line strip between antennas in the same plane [20]. In this work, combination of a line strip between antennas in the top plane with EBG in the ground plane for further reduc- 
tion in mutual coupling is proposed. A copper line strip of width $1 \mathrm{~mm}$ is introduced between two radiating patches as shown in Fig. 10.

Return loss and transmission coefficient of the proposed MIMO antenna is plotted versus frequency in Fig. 11(a) and 11(b), respectively. This is evident from the plots that resonant frequency remains unaffected due to introduction of line strip. Moreover, magnetic field between the two patches gets trapped in the line strip and results in additional enhancement of isolation by $16.2 \mathrm{~dB}$.
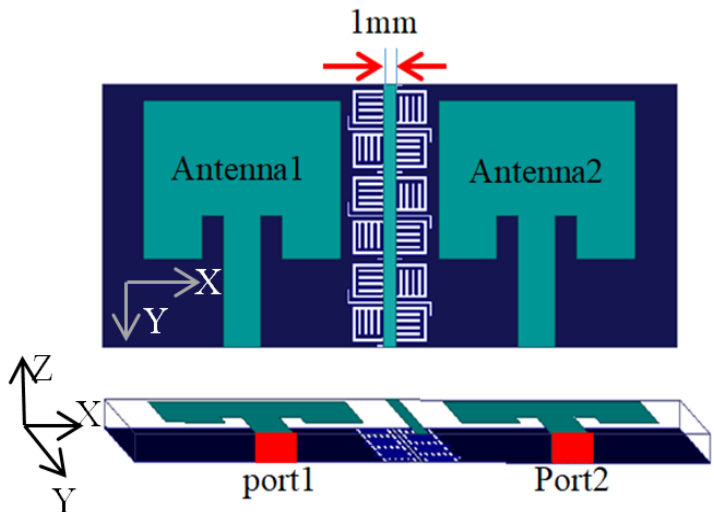

Fig. 10. Microstrip patch MIMO antenna for WLAN: front view with the metal strip of width $1 \mathrm{~mm}$.

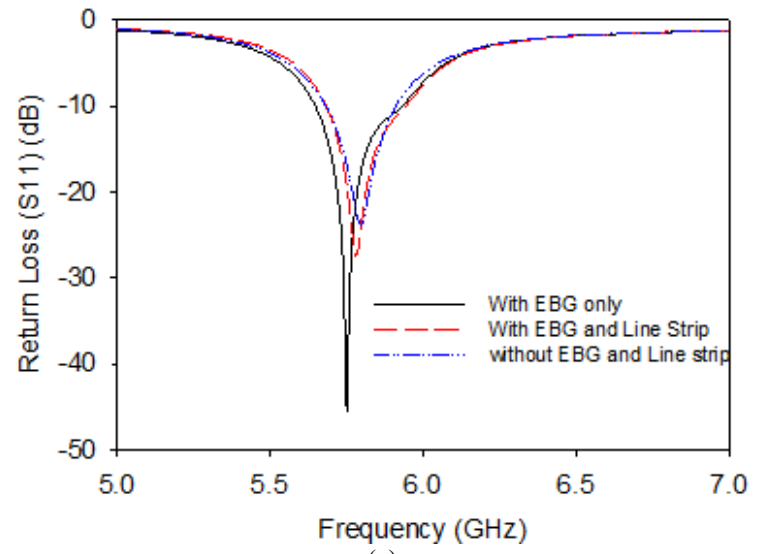

(a)

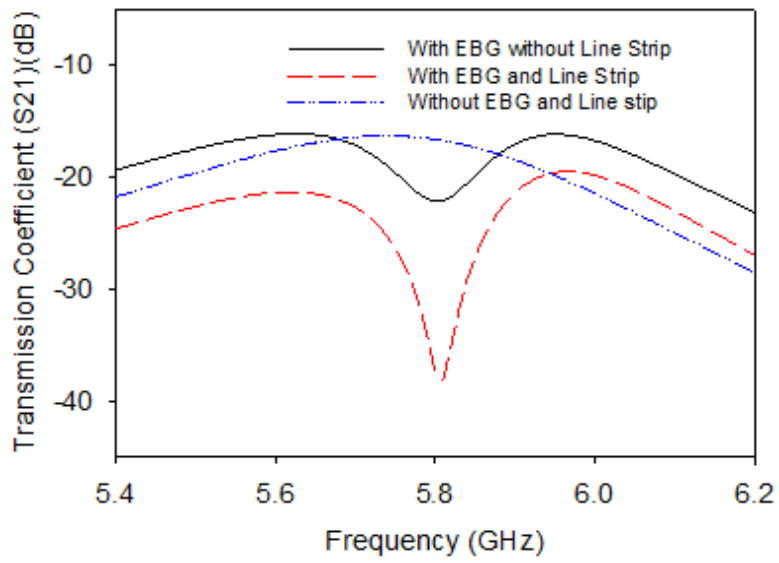

(b)

Fig. 11. Simulated (a) return loss (S11) and (b) transmission coefficient (S21) of MIMO antenna with and without the proposed EBG.

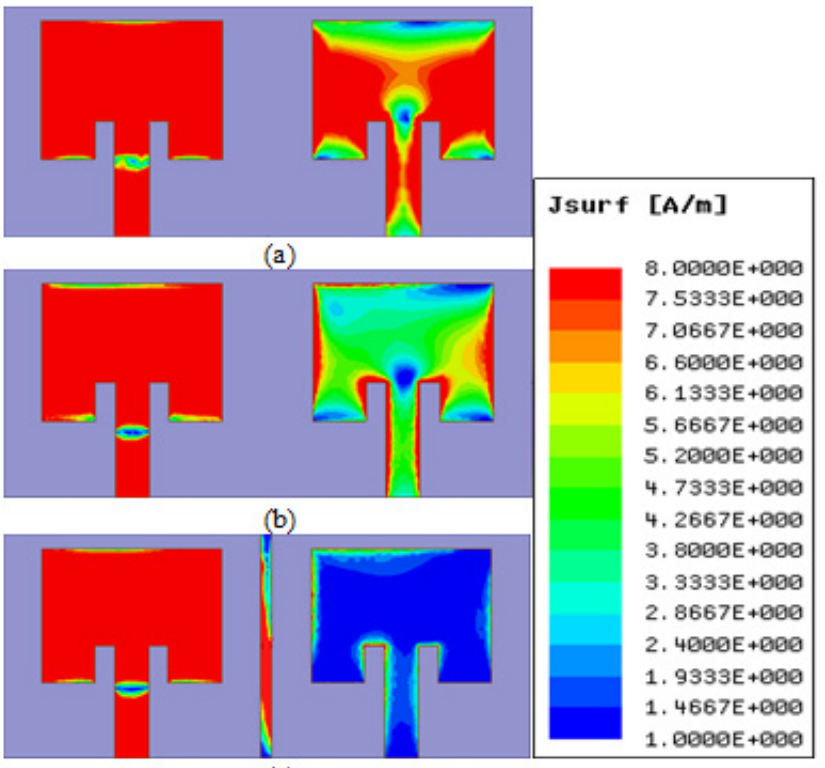

(c)

Fig. 12. Top view of the surface current distribution in radiating patches in MIMO antenna (a) without the proposed EBG, (b) with the proposed EBG and without the line strip, (c) with the proposed EBG and the line strip.

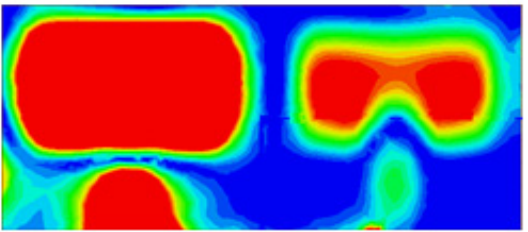

(a)

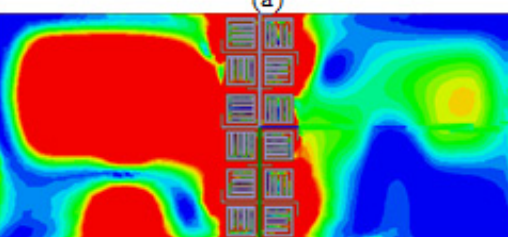

(b)



(c)

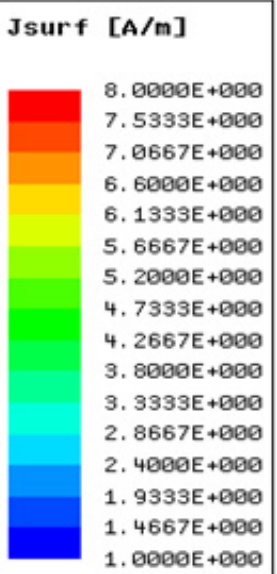

Fig. 13. Bottom view of the surface current distribution: (a) without the proposed EBG, (b) with the proposed EBG and without the line strip, (c) with the proposed EBG and the line strip.

Hence, the total enhancement of $21.8 \mathrm{~dB}$ is achieved due to combination of EBG and line strip.

Surface current distribution on radiating patches and ground is shown in Fig. 12 (top view) and Fig. 13 (bottom view), respectively. Antennal is excited through port 1 and antenna 2 is terminated with $50 \Omega$ matched load at port 2 . It is observed from Fig. 12(a) and Fig. 13(a) that strong mutual coupling is present between antennas without EBG. In Fig. 12(b) and 13(b) EBG is used in ground plane and moderate reduction in mutual coupling is observed from 
the surface current distribution. With EBG in ground plane and strip line in between antenna patches in the same plane, considerable reduction of mutual coupling is observed in Fig. 12(c) and Fig. 13(c). In Fig. 12(c), it is evident that magnetic field is getting trapped in the line strip which results in higher surface current density on the line strip and it helps in reducing mutual coupling between antennas.

\section{MIMO Antenna Fabrication and Result Analysis}

The fabricated prototype of the MIMO antenna without EBG, with EBG in the ground plane and the proposed antenna containing combination of EBG and line strip is shown in Fig. 14(a), (b) and (c), respectively. Dielectric material used for fabrication is low cost FR4 substrate with dielectric constant 4.4, thickness $1.6 \mathrm{~mm}$ and loss tangent of 0.01 . Return loss and transmission coefficient is measured for all fabricated antennas using vector network analyzer. Measurement setup is shown in Fig. 14(d).

Simulated and measured values of return loss and transmission coefficient are plotted and compared in Fig. 15(a) and (b), respectively. Figure 15(a) shows that simulated and measured return loss (S11) of the MIMO antenna is unaffected by the use of combination of EBG and line strip. In Fig. 15(b) transmission coefficient (S21) vs. frequency plot shows that the MIMO antenna without EBG is having measured isolation of $-14.4 \mathrm{~dB}$ which is comparable to simulated isolation of $16.5 \mathrm{~dB}$ at $5.8 \mathrm{GHz}$. Measured mutual coupling gets reduced to $-39.6 \mathrm{~dB}$ by the use of combination of EBG and line strip. Hence maximum

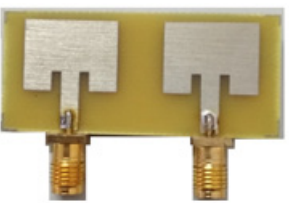

(a)

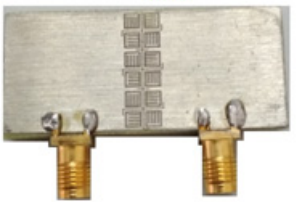

(b)

(c)

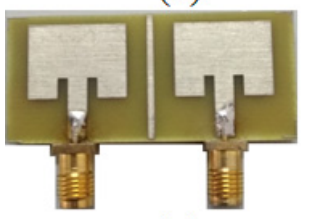

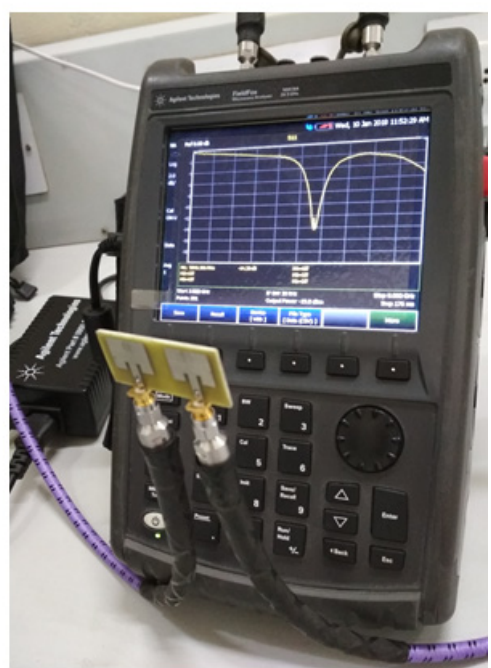

(d)
Fig. 14. Fabricated prototype. (a) Top view of the MIMO antenna without the proposed EBG and the line strip. (b) Back view of the MIMO antenna with the EBG. (c) Top view of the MIMO antenna with the proposed EBG and the line strip. (d) Measurement setup with VNA.

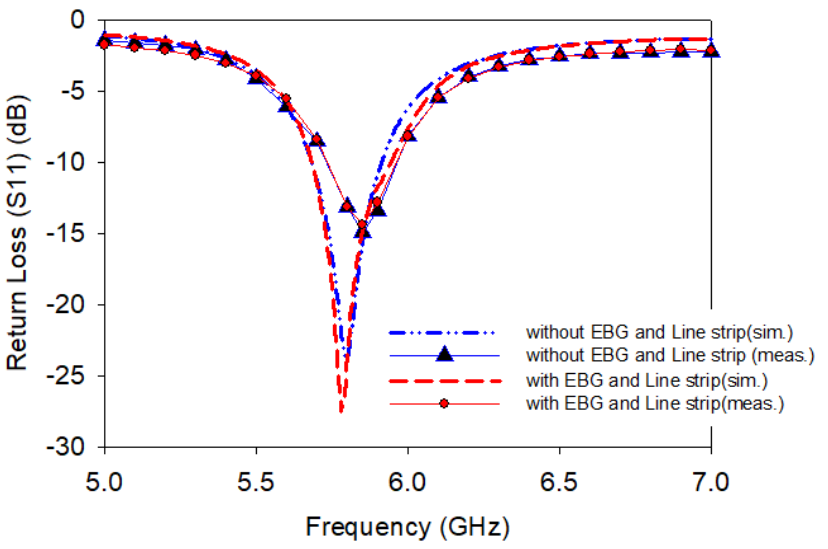

(a)

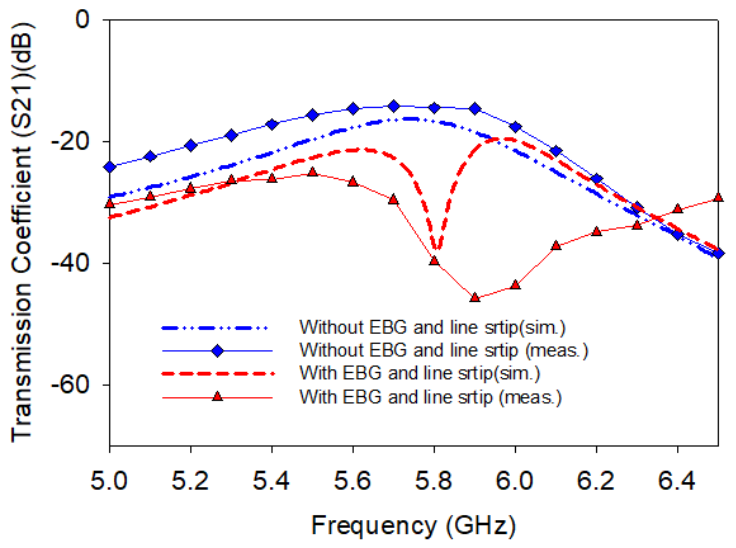

(b)

Fig. 15. Measured (a) return loss and (b) transmission coefficient of the MIMO antenna with and without the proposed EBG and the line strip.

of $25.2 \mathrm{~dB}$ enhancement in measured isolation is obtained which is comparable to simulated isolation of $21.8 \mathrm{~dB}$.

For MIMO antenna application, envelope correlation coefficient (ECC) is a paramount factor because of its direct relation with the loss in spectral efficiency and degradation of performance of MIMO antenna system. The envelope correlation coefficient $\left(\rho_{\mathrm{e}}\right)$ can be computed using S-parameters [21], [22] by (1).

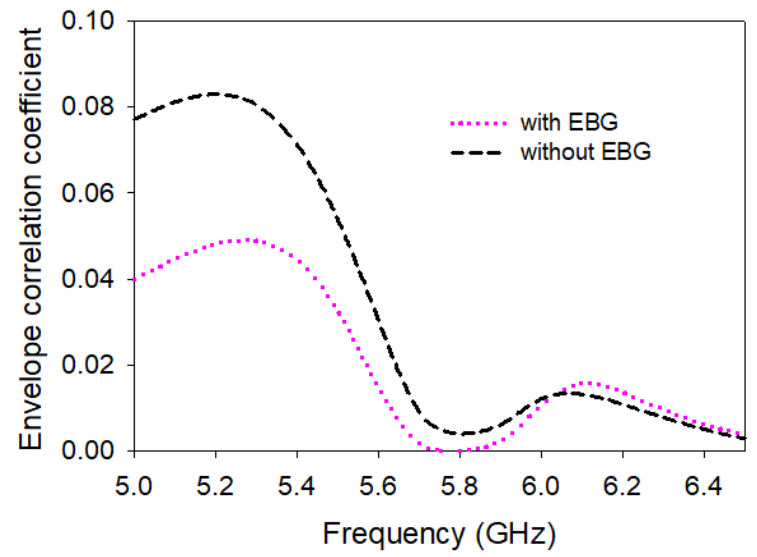

Fig. 16. Correlation coefficient of basic MIMO antenna (without EBG) and the proposed MIMO antenna (with EBG). 


$$
\rho_{\mathrm{e}}=\frac{\left|S_{11}^{*} S_{12}+S_{21}^{*} S_{22}\right|}{\left(1-\left|S_{11}\right|^{2}-\left|S_{21}\right|^{2}\right)\left(1-\left|S_{22}\right|^{2}-\left|S_{12}\right|^{2}\right)}
$$

Figure 16 shows the variation of envelope correlation coefficient with frequency with and without use of the combination of EBG and line strip. The value of $\rho_{\mathrm{e}}$ is less than 0.01 for both the cases.

With increase in number of elements in MIMO system the channel capacity can be improved. However, the presence of uncorrelated MIMO channels will induce loss to the channel capacity. The channel capacity loss $\left(C_{\text {loss }}\right)$ can be evaluated [21], [22] by using (2) and (3):

$$
C_{\text {loss }}=-\log _{2} \operatorname{det}\left(\Psi^{\mathrm{R}}\right)
$$

where $\boldsymbol{\Psi}^{\mathrm{R}}$ is the receiving antenna correlation matrix that is given by

$$
\boldsymbol{\Psi}^{\mathrm{R}}=\left[\begin{array}{cc}
\left(1-\left|S_{11}\right|^{2}-\left|S_{21}\right|^{2}\right) & -\left(S_{11}^{*} S_{12}+S_{21}^{*} S_{22}\right) \\
-\left(S_{22}^{*} S_{21}+S_{12}^{*} S_{11}\right) & \left(1-\left|S_{22}\right|^{2}-\left|S_{12}\right|^{2}\right)
\end{array}\right] .
$$

The computed channel capacity loss $\left(C_{\text {loss }}\right)$ is less than $0.1 \mathrm{bps} / \mathrm{Hz}$ for the operating frequency of $5.8 \mathrm{GHz}$ (with and without use of EBG) as shown in Fig. 17.

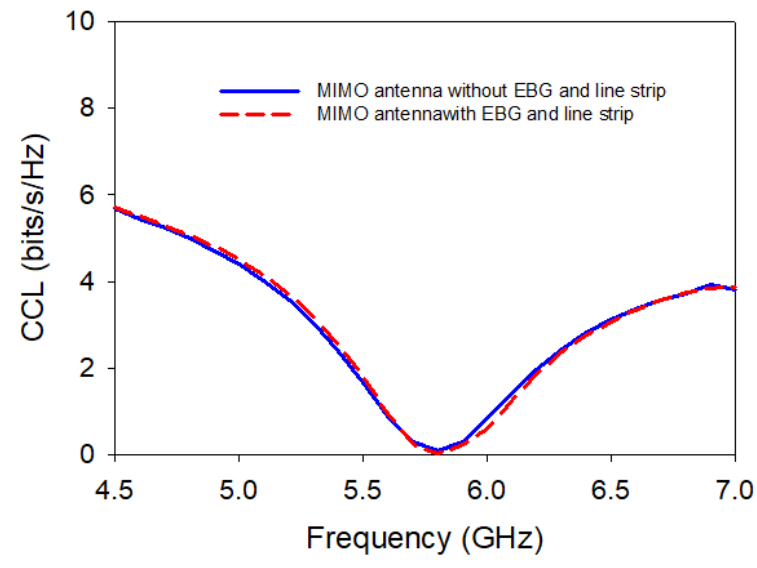

Fig. 17. Channel capacity loss (CCL) of MIMO antenna with and without EBG and line strip.

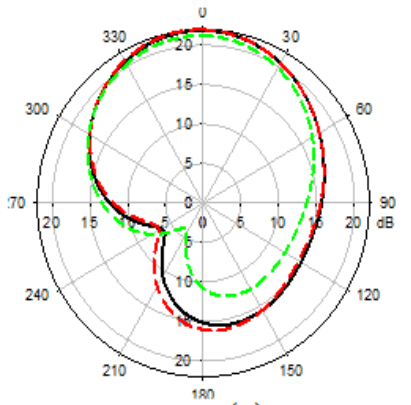

(a)

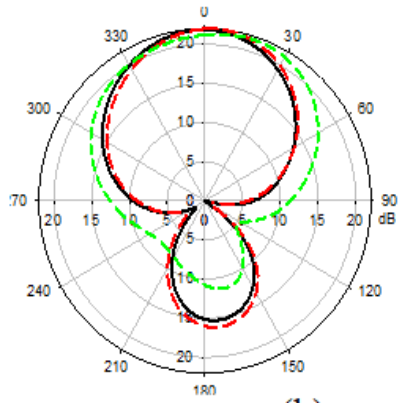

(b)

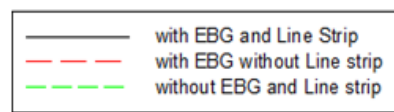

Fig. 18. (a) E-plane and (b) H-plane radiation pattern of MIMO antenna with and without EBG and line strip.

\begin{tabular}{|c|c|c|c|c|}
\hline Ref. no. & $\begin{array}{c}\text { Center } \\
\text { freq. } \\
\text { (GHz) }\end{array}$ & $\begin{array}{c}\text { Substrate } \\
\text { relative } \\
\text { dielectric } \\
\text { constant }\end{array}$ & $\begin{array}{c}\text { Edge to } \\
\text { edge } \\
\text { spacing } \\
\left(\boldsymbol{\lambda}_{\mathbf{0}}\right)\end{array}$ & $\begin{array}{c}\text { Coupling } \\
\text { suppression } \\
\text { in H-plane } \\
\text { (dB) }\end{array}$ \\
\hline$[2]$ & 3.5 & 2.65 & 0.12 & 9.7 \\
\hline$[3]$ & 2.8 & 4.4 & 0.093 & 9 \\
\hline$[5]$ & 2.8 & 4.4 & 0.056 & 9 \\
\hline$[7]$ & 5 & 2.65 & 0.22 & 16 \\
\hline$[9]$ & 5.8 & 4.4 & 0.5 & 11 \\
\hline proposed & 5.8 & 4.4 & 0.15 & 21.8 \\
\hline
\end{tabular}

Tab. 2. Comparison of the proposed work with existing designs.

Figure 18 depicts the radiation pattern in $\mathrm{E}$ and $\mathrm{H}-$ plane of one of the MIMO antenna (other is matched with $50 \Omega$ load) with and without EBG and line strip at $5.8 \mathrm{GHz}$. The main lobe of the antenna remains unaltered and back radiation of the antenna is slight increased due to EBG in the ground plane. Hence the radiation pattern has a little effect due to EBG and line strip.

\subsection{Comparison of the Proposed Work with Existing Designs}

Performance of existing MIMO antennas with different electromagnetic bandgap structures in terms of center frequency, used dielectric material, edge to edge spacing and coupling reduction is compared with the proposed antenna in Tab. 2. In [2] and [7] dielectric constant which is used is less cost effective and also the coupling suppression is less than $10 \mathrm{~dB}$. In [3] and [5] the center frequency is $2.8 \mathrm{GHz}$ and coupling suppression is less than $20 \mathrm{~dB}$. An additional $9 \mathrm{~dB}$ isolation is achieved compared to [9] by adding a metal line strip in one side of the antenna. So isolation enhancement of the proposed method of combining UC-EBG with a line strip outperforms the state-of-theart works.

\section{Conclusion}

A new method of using UC-EBG structure with a line strip is proposed for significant reduction in mutual coupling of MIMO antenna in H-plane for WLAN application. Design of UC-EBG with equivalent circuit is presented. Transmission line analysis of UC-EBG shows that frequency of resonance is tunable and can be used for other frequencies as well. The band gap is also validated using reflection phase diagram and dispersion diagram. Basic MIMO antenna design is taken for analysis and EBG structure has been etched out of the ground plane. It helps in reducing mutual coupling in H-plane. For further mutual coupling reduction a line strip is placed in between the radiating patches of MIMO antenna. Fabrication of all the structures is done with low cost FR4 substrate. Measured values are in good match with simulated values. Lower 
design cost and compact size with better radiation and isolation properties (envelope correlation coefficient and channel capacity loss) makes the proposed method a good candidate for MIMO antenna performance enhancement.

\section{References}

[1] LUO, C. M., HONG, J. S., ZHONG, L. L. Isolation enhancement of a very compact UWB-MIMO slot antenna with two defected ground structures. IEEE Antennas and Wireless Propagation Letters, 2015, vol. 14, p. 1766-1769. DOI: 10.1109/LAWP.2015.2423318

[2] XU, H. X., WANG, G. M., QI, M. Q. Hilbert-shaped magnetic waveguided metamaterials for electromagnetic coupling reduction of microstrip antenna array. IEEE Transactions on Magnetics, 2013, vol. 49, no. 4, p. 1526-1529. DOI: 10.1109/TMAG.2012.2230272

[3] QAMAR, Z., PARK, H. C. Compact waveguided metamaterials for suppression of mutual coupling in microstrip array. Progress In Electromagnetics Research, 2014, vol. 149, p. 183-192. DOI: 10.2528/PIER14063002

[4] QAMAR, Z., NAEEM, U., KHAN, S. A., et al. Mutual coupling reduction for high performance densely packed patch antenna arrays on finite substrate. IEEE Transactions on Antennas and Propagation, 2016, vol. 64, no. 5, p. 1653-1660. DOI: 10.1109/TAP.2016.2535540

[5] GHOSH, J., GHOSAL, S., MITRA, D., et al. Mutual coupling reduction between closely placed microstrip patch antenna using meander line resonator. Progress In Electromagnetics Research Letters, 2016, vol. 59, p. 115-122. DOI: 10.2528/PIERL16012202

[6] AL-HASAN, M. J., DENIDNI, T. A., SEBAK, A. R. Millimeterwave compact EBG structure for mutual coupling reduction applications. IEEE Transactions on Antennas and Propagation, 2015, vol. 63, no. 2, p. 823-828. DOI: 10.1109/TAP.2014.2381229

[7] YANG, X., LIU, Y., XU, Y. X., GONG, S. X. Isolation enhancement in patch antenna array with fractal UC-EBG structure and cross slot. IEEE Antennas and Wireless Propagation Letters, 2017, vol. 16, p. 2175-2178. DOI: 10.1109/LAWP.2017.2703170

[8] ZHANG, J., CI, G., CAO, Y., et al. A wide band-gap slot fractal UC-EBG based on Moore space-filling geometry for microwave application. IEEE Antennas and Wireless Propagation Letters, 2017, vol. 16, p. 33-37. DOI: 10.1109/LAWP.2016.2553135

[9] KUMAR, N., KIRAN KOMMURI, U. MIMO antenna mutual coupling reduction for WLAN using spiro meander line UC-EBG. Progress In Electromagnetics Research C, 2018, vol. 80, p. 65-77. DOI: 10.2528/PIERC17101601

[10] ARORA, A., KUMAR, N. To reduce mutual coupling in microstrip patch antenna arrays elements using electromagnetic band gap structures for X-band. In 2017 International Conference on Nextgen Electronic Technologies: Silicon to Software (ICNETS2). Chennai (China), 2017, p. 228-230. DOI: 10.1109/ICNETS2.2017.8067937

[11] KUSH, C., PRATHIBHA, P., KUMAR, N. Wideband antenna with notches at frequencies of existing services band using EBG. In 2015 International Conference on Communications and Signal Processing (ICCSP). Melmaruvathur (India), 2015, p. 1407-1411. DOI: $10.1109 /$ ICCSP.2015.7322742

[12] FARAHANI, H. S., VEYSI, M., KAMYAB, M., et al. Mutual coupling reduction in patch antenna arrays using a UC-EBG superstrate. IEEE Antennas and Wireless Propagation Letters, 2010, vol. 9, p. 57-59. DOI: 10.1109/LAWP.2010.2042565
[13] MOHAMADZADE, B., AFSAHI, M. Mutual coupling reduction and gain enhancement in patch array antenna using a planar compact electromagnetic bandgap structure. IET Microwaves, Antennas \& Propagation, 2017, vol. 11, no. 12, p. 1719-1725. DOI: 10.1049/iet-map.2017.0080

[14] Li, Q., FERESIDIS, A. P., MAVRIDOU, M., HALL, P. S. Miniaturized double-layer EBG structures for broadband mutual coupling reduction between UWB monopoles. IEEE Transactions on Antennas and Propagation, 2015, vol. 63, no. 3, p. 1168-1171. DOI: 10.1109/TAP.2014.2387871

[15] MAVRIDOU, M., FERESIDIS, A. P. GARDNER, P. Tunable double-layer EBG structures and application to antenna isolation. IEEE Transactions on Antennas and Propagation, 2016, vol. 64, no. 1, p. 70-79. DOI: 10.1109/TAP.2015.2496619

[16] LEE, J., KIM, S., JANG, J. Reduction of mutual coupling in planar multiple antenna by using 1-D EBG and SRR structures. IEEE Transactions on Antennas and Propagation, 2015 vol. 63, no. 9, p. 4194-4198. DOI: 10.1109/TAP.2015.2447052

[17] ISLAM, M. T., ALAM, M. S. Design of high impedance electromagnetic surfaces for mutual coupling reduction in patch antenna array. Materials, 2013, vol. 6, p. 143-155. DOI: $10.3390 / \mathrm{ma} 6010143$

[18] XIE, H.-H., JIAO, Y.-C., SONG, K., YANG, B. Miniature electromagnetic band-gap structure using spiral ground plane. Progress In Electromagnetics Research Letters, 2010, vol. 17, p. 163-170. DOI: 10.2528/PIERL10081203

[19] KOVÁCS, P., URBANEC, T. Electromagnetic band gap structures: Practical tips and advice for antenna engineers. Radioengineering, 2012, vol. 21, no. 1, p. 414-421. ISSN: $1210-2512$

[20] ARUN, H. SARMA, A. K., KANAGASABAI, M., et al. Deployment of modified serpentine structure for mutual coupling reduction in MIMO antennas. IEEE Antennas and Wireless Propagation Letters, 2014, vol. 13, p. 277-280. DOI: 10.1109/LAWP.2014.2304541

[21] SEE, C. H., ABD-ALHAMEED, R. A., ABIDIN, Z. Z., et al. Wideband printed MIMO/diversity monopole antenna for WiFi/WiMAX applications. IEEE Transactions on Antennas and Propagation, 2012, vol. 60, no. 4, p. 2028-2035. DOI: 10.1109/TAP.2012.2186247

[22] WU, W. J., YUAN, B., WU, A. A quad-element UWB-MIMO antenna with band-notch and reduced mutual coupling based on EBG structures. International Journal of Antennas and Propagation, p. 1-10. DOI: 10.1155/2018/8490740

\section{About the Authors...}

Niraj KUMAR pursued his B.Sc. (Engg.) in Electronics and Communication Engineering from MIT Muzaffarpur and M.Tech. in RF and Microwave Engineering from IIT Kharagpur in the year 2008 and 2010, respectively. He is currently pursuing Ph.D. and working as an Assistant Professor in the School of Electronics Engineering, Vellore Institute of Technology Chennai Campus, Chennai, India. $\mathrm{He}$ has more than 8 years of teaching experience. His research interests include microwave integrated circuits, planar antennas and electromagnetic band gap structures.

Usha Kiran KOMMURI received her Ph.D. in Microwave Electronics from Gulbarga University, Karnataka, India in 2007. Later, she has joined as Project scientist in Micro- 
wave Lab, ECE, Indian Institute of Science (IISc) Bangalore, India and completed several projects. Currently she is working as an Assistant Professor (Sr.) in the School of Electronics Engineering (SENSE), Vellore Institute of Technology, Chennai Campus, Chennai, India. She has more than 10 years of teaching and research experience. Her research area includes, microwave integrated circuits, planar antenna, RF MEMS, metamaterials, electromagnetic band gap structures, frequency selective surfaces (FSS), high impedance surfaces (HIS), etc. 